is due to the fact that there is a marked loss of electromotive force in the battery. Thus the charging current had 9i volts, while the discharging current had only $6 \mathrm{r}^{\cdot} 5$ volts. It follows, from a consideration of the theory of the battery and the formula-

$$
a=\frac{\mathrm{I}^{\prime}\left(\mathrm{E}^{\prime}-\mathrm{R}^{\prime} \mathrm{I}^{\prime}\right) t^{\prime}}{\mathrm{I}(\mathrm{E}-\mathrm{RI}) t}
$$

that the efficiency must always be less than unity, but may be greater as the intensities and resistances are less. In the formula, $E$ is the E.M.F. of the battery, $R$ its internal resistance, I and $t$ the intensity of the current and its duration during charge, while the same letters marked serve for the corresponding quantities during discharge. It is therefore advantageous to charge the battery with a feeble current flowing for a long time. It was observed also, that the resistance of the battery was lower during discharge than charge.

To sum up, the charge of the battery requires a total mechanical work of 1.558 horse-power during $22 \mathrm{~h}$. $45 \mathrm{~m}$., which is equivalent to a horse-power during $35 \mathrm{~h} .26 \mathrm{~m}$. The battery only received 66 per cent. of the total work expended, the rest being lost in overcoming passive resistances, and exciting the field magnets. Only 60 per cent. of this power stored was yielded back by the battery, and there is reason to believe that the same result will be forthcoming in all applications similar to lighting by Maxim lamps.

\section{THE WILD SILKS OF INDIA ${ }^{1}$}

$\mathrm{THE}$ laudable efforts of the Indian Government to utilise the various products of which these wild silks form a class will tend, by the immediate production of wealth, and yet more by the spirit of intercommunication and enterprise thus created, to overcome the great difficulty of poverty and still greater difficulty of isolation, which so tasked its efforts in the last famine. And this work is the more desirable because, as the last census shows, the peaceful, firm rule of the British in India has removed that natural check to population which was found of old in the mutual internecine wars of its peoples; and numbers have increased to such an extent that the failure of a crop over any wide district is invariably followed now by a famine.

The principal varieties of wild silks found in India are the Tusser, or Tasar, the Eria, and the Muga, or Moonga, silks, besides several others, at present of little commercial importance.

Silk differs from all other materials used in textile fabrics in the nature of the thread as originally produced. Hemp, flax, cotton, wool, and many other threads are produced by the twisting tightly together of the short but very fine fibres of the raw material, the untwisting of which reduces the thread again to short loose fragments. The long fibre of the best Sea-Island cotton does not much exceed $1 \frac{1}{2}$ inches in length. Silk, on the other hand, is spun by the silkworm (except that it is not a worm, and does not spin it!) in one long thread: threequarters of a mile is quoted by Mr. Wardle as the length of the thread of a Tusser worm. There is no "spinning" in the process at all, but two fine threads come from the spinnarets of the grub as from the spinnarets of a spider in such a glutinous semi-liquid condition that they coalesce into one thread, which, in the best kind of silkworms, can be wound without a break from the outside of the suspended cocoon to where the grub left off spinning and turned into a chrysalis. The silk-reeler does not, even in the coarse Tusser variety, reel off a cocoon of this singly, but from four to six together, whose gummy surfaces make them combine into a single thread still fine. 1 "Handbook of the Collection Illustrative of the Wild Silks of India in
he Indian Section of the South Kensington Museum," by Thomas Wardle. (Eyre and Spottiswoode, r88r.)
The Eria cocoon is not found practically so available for this treatment, but, in addition to the beautiful continuous thread of the Bombyx or Tusser silkworm, the waste part of their cocoons can be treated like the vegetable fibres (cotton, \&c.) of which we spoke with equally good results as a textile material, and with nearly all the beauty of the perfect silk thread. For this purpose the whole of the cocoon of the Eria is specially available, and, instead of being carefully reeled off, it is cut up or torn into shreds by the carding machine, and then treated as a long staple cotton. This is known as spun silk, or by the more recent name of Schappe. If, however, the surface of such a thread is examined, even with small magnifying power, it will show the loose ends of the fibres sticking out in every direction; and although they are individually too fine to attract the attention of the naked eye, in combination they are quite patent to the finger and to the ear, a soft deadness resulting instead of the sharp whistle of the natural silk, on which are no fibres except the ends left by careless throwsters.

Another inferiority of spun silk, though not a great one in the ever-changing fashionable world of England, is that it has not the durability which distinguishes the continuous silk thread. Yet in India garments made from the former are handed down from mother to daughter!

The Tusser or Tusseh larva, whose coarse, strong thread is available for thrown silk, is a monster compared with the larva of the Bombyx mori, or common silk-worm, It measures 7 inches in length and $\mathbf{I}$ inch in diameter; the wings of the moth-a very handsome one-are 7 inches across, and the thread also is three times as coarse, and three times as strong as that of the China silkworm. Here, however, comes an objection to it in the eye of the manufacturer. While the thread of the Bombyx is almost round, the extra coarseness of the Tusser thread all consists in its extra width : it is, in fact, three times as broad as it is thick. Like any thread of this shape compared with a round one, it has a great tendency to split, and consequently become rough in working. Another difficulty to both reelers and dyers is caused by the substantial way in which the Tusser grub forms its cocoons. Major Coussmaker observes that-

"As the chrysalis remains in the cocoon as long as eight months, exposed to the hottest sun and occasional thunderstorms, the cocoon had need to be made a hard impenetrable material; so indestructible is it, that Bheels and other tribes which live in the jungles, use the cocoon as an extinguisher to the bamboo tube in which they keep the 'falita' or cotton tinder used by them for lighting their tobacco and the slow matches of their matchlocks. The cocoon is also cut into a long spiral band, and used for binding the barrel of matchlocks to the stocks, being, as the natives say, unaffected either by fire or water. . . . After the caterpillar has spun a layer of silk thick enough to conceal itself, it discharges some kind of gum or cement, thick like plaster of Paris, and with its muscular action it causes this secretion to thoroughly permeate the whole cocoon and solidify the wall. In this manner it goes on spinning layer after layer of loops, and cementing them altogether until the whole of its silk is exhausted, and the wall of the cocoon becomes so hard that it requires a sharp penknife to cut through it" ( $p p$. I8, I9).

Again, in a later report (February 2I, I880), Major Coussmaker writes :-

"One of the most interesting, and I think important, facts that I have this year been able to prove, is with regard to the composition of the cement with which the caterpillar hardens its cocoon. Former analyses of this agent made for me, in England by Dr. Taylor, and in Bombay by Dr. Lyon, had shown that it contained the acid urate of ammonia, that it was in fact excrementitious; and this year, by opening the cocoons at various intervals, I was able to convince myself of the fact that when the caterpillar has left off feeding and begins to spin, it voids 
the food remaining in the alimentary canal, first of all in a more or less solid form and of a dark colour, but after it has become fully enveloped in the cocoon the excrement comes away as a light-coloured liquid, the hue and consistency of which depend upon the amount of vegetable matter not previously evacuated and the amount of lime, carbon, and ammonia present. The respective proportions of these ingredients vary, I presume, with the food upon which the caterpillar has fed, and with the state of the atmosphere at the time of spinning; also the longer they remain coating the fibre the harsher and more discoloured it will be. It is therefore very necessary, I think, to remove this cement at a very early date; and this chemistry has shown the manufacturers how to do. Judicious feeding too may alter its nature. Before long, fresh cocoons will be at an early stage thoroughly cleansed from all discolouring matter, and Tasar silk will be available for manufacturing purposes as colourless as it is when first put forth by the caterpillar" (p. 21).

At any rate here is a fine field for both economic and philosophical results for both the chemist and the naturalist.

There are two crops of Tusser silk in the year, i.e. two generations of grubs pass from the egg to the imago, whereas the Bombyx of commerce so passes only once. The moth is considered a sacred insect, and it is interesting to read of the long series of ascetic ordinances connected with the attendance upon it, the failure to observe which will bring down the anger of the gods and destruction upon the cultivators. Yet the grubs are said to flourish better out-of-dcors than under the roof and care of men, and are found feeding upon seventeen different species of trees growing wild over various parts of Hindostan. It is much more practicable and hopeful to engage the unenterprising natives in its collection under these conditions than if the elaborate art with which the Chinese cultivate the Bombyx were required.

The silk of the Eria and Moonga or Muga cocoons is softer and of a clearer colour than the Tusser silk, but lacks the strength of that very coarse variety. It dyes well, but is difficult to wind. In all respects therefore it is easier to work it up into spun silk.

The favourite food of the Eria is the Palma Christi or castor oil plant, Ricinis communis. So productive is this worm that it sometimes gives twelve broods, i.e. generations, in a year.

The Muga worm breeds five times; the colour of the silk varies with the food, some of it retaining its drabby colour till the last. The moths of all these genera are large and handsome. The magnificent Attacus atlas moth, called in France Le Géant des Papillons, measures upwards of ten inches in expanse of wing. It is a common idea that moths eat their way out of their cocoons, and that all permitted to do so spoil their silk; but even in the case of the solid cocoon of the Tusser moth it is observed that " after eight or nine months in the pupa state a moist spot is observed at one end of the cocoon. The moth is now about to emerge both from its pupa shell and from the cocoon. It secretes an acid fluid which softens the cement of the cocoon, and enables it to separate the fibres sufficiently to allow of its creeping out" (p. I9). Capt. Brooke also says that "in Seonee the pierced cocoons are wound, and that no koshtee rejects a cocoon simply because the moth has eaten its way through it. ... It does not eat its way out but separates the fibres with its legs and wing-spine, and so creeps out. It has neither teeth nor mouth proper" (p. 26). More remarkable still is the provision made by the larva of this Attacus atlas, "the upper extremity of whose cocoon forms a natural orifice for the exit of the moth, made by the conveyance of a great number of silk fibres which are left ungummed, and are thus soft and flossy; thus the exit of the imago leaves no disturbance behind", (p. 63).

The most interesting question, of course, is, how far care and industry can improve this imperfect natural wealth. The strongest proof of the value of such education is to be found in the fact that the beautiful Italian and French silks, whose fineness and regularity insure for them a price 50 per cent. higher than the best China silks, are the lineal descendants of the eggs brought from China in the reign of Justinian. The destruction caused among them by the dreadful disease, pebrine, has necessitated the import into Europe of Japanese eggs, the drabby colour of the silk of which marred all the efforts of the dyer to obtain clear delicate tints, especially in different shades of white; but careful attention and artificial selection are bringing them near to equality with the pure European silk; and Major Coussmaker in Pooneh has succeeded in obtaining perfectly white Tusser silk by causing the caterpillar to void all its excrement before spinning.

The special fitness of Tusser silk for the dark dull colours now fashionable is most optimistically expressed by $\mathrm{Mr}$. Wardle in the phrase that "Tusser silk properly dyed inberently takes shades of artistic merit." Is dirt then beauty? and purity and brilliancy essentially vulgar?

There can be little doubt that European skill and machinery would more than balance the cheapness of Indian labour, which could be trusted to produce only the commonest qualities of thrown silk. It is also far safer and less likely to end in failure or discouragement to make spun silk the object of Indian produce than to attempt to rival the beautiful productions of Italy and China.

One cannot help noticing with satisfaction in this concise history the working together for good of such widely separated parties as, in India, the high Government official, the investigating naturalist, the active military officer in charge of a district; then the organising British manufacturer, who brings into willing co-operation the Italian throwster, the Leek dyer, the Halifax weaver, the London artist, not to mention the taste and skill of the ladybountiful of her neighbourhood.

W. ODELL

\section{NOTES}

ON Tuesday evening, April II, the public thoroughfare stretching between Hatton Garden and the Old Bailey was lighted for the first time by the electric light. The novelty of the installation was the fact that the incandescent system had been adofted in preference to the arc system. Mr. E. H. Johnson, the agent of the Edison Electric Light Company, has in fact made a public demonstration of the Edisin system by lighting up a district of London in the same way as by gas. In addition to the street lights, the different premises lining the street are also lighted; for example, the City 'lemple Church, Messrs. Negretti and Zambra's, Messrs. Spiers and I'ond's. In all there are 936 incandescent lamps, and these are fed by one of the large dynamos stationed at No. 57, Holborn, the distributing centre of the company. These large generators are made upon the same plan as the smaller ones recently described by us, and are driven by Porter engines. They yield a current of 1025 amperes. The resistance of each lamp whitehot is 140 ohms, and as this is much greater than the hot resistance of other incandescent lamps, the resistance of a long circuit is not so relatively high as in other systems, and hence there is less need of large leads. The cost of copper for conductors is an important item in electric lighting, but should copper conductors become too expensive to use, Mr. Edison intends to employ iron, say old iron rails. Mr. E. H. Johnison states that the company intend to manufacture and supply electricity for all kinds of purposes, and judging from experience gathered in New York, where a district is lighted by this system, the profits from the sale of electricity for power purposes alone will pay the company's dividends, so that they can afford to give the light for notbing. This remark is a rejoinder to those 